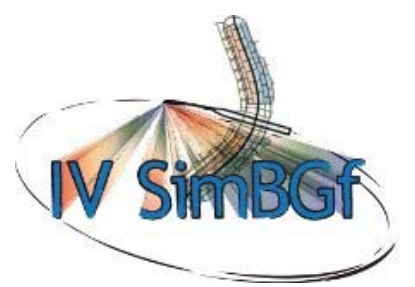

\section{SISMICIDADE DE MOÇAMBIQUE}

\author{
Viriato Samboco \\ Direcção Nacional de Geologia (DNG)
}

\section{ABSTRACT}

Mozambique is situated in southern Africa and is crossed by the African Rift Valley which is primarily responsible for a significant seismic activity in the territory, located in three regions, north, center and south of the country, with the occurrence of catastrophic earthquakes originated in continental tectonic structures and underwater. The seismicity is monitored by a network of seismographic stations that has undergone several changes over this decade and currently a limit of detectability rather low. The recent seismic activity is located mainly in central and northern territory, it is possible to highlight several areas of highest concentration epicenter. In general, the quality of the locations of hypocenters on land is higher than the locations of submerged areas, highlighting the need of installing more seismograph stations permanent. Despite some constraints, information from recent instrumental seismicity can be used in various studies that contribute to seismic hazard assessment in Mozambique and the region in general. The results are presented as maps of seismic risk in terms of Peak Ground Acceleration (PGA) for the mean and 85th percentile. The distribution of PGA values indicate relatively high risk along the African rift system. In parts of northern rift system, which exceed 250 gallons of $10 \%$ probability of exceedance in 50 years.

\section{Introdução}

Moçambique encontra-se localizado numa região propensa a ocorrência de sismos devido a sua localização geográfica e tectónica, limitada pelas coordenadas $10^{\circ}-27^{\circ} \mathrm{S}$ e $30^{\circ}-42^{\circ} \mathrm{E}$, atravessado pelo Rift africano e circundada por placas tectonica de Nubia, Somália e Antartica (Figura 1). Nesta região os epicentros dos sismos não estão distribuidos equitativamente, ressaltando duas zonas com maior concentração de sismos, nomeadamente centro e norte do Pais. Contudo, a sismicidade de Moçambique não é muito intensa, mas sim é muito frequente em algumas regiões do centro e norte do País. No entanto, o território tem sido atingido por diversos sismos com elevada magnitude e intensidade, tendo sido detectados eventos desde 1957 com a instalação do primeiro observatório sismológico de Lourenço Marques, actual Maputo.

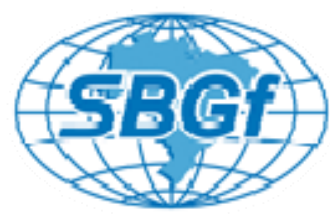

\section{Metodologias}

A avaliação do risco sísmico para o territorio moçambicano, foi feito usando a abordagem probabilística, baseando-se nos dados instrumentais recolhidos pelas redes sismológicas locais e regionais e, para sismos com epicentros mais afastados relativamente às redes, ou possuidores de magnitudes mais elevadas, pelas redes globais, e compilados os dados em boletins e catálogos sismológicos da região. A localização dos eventos sísmicos e o cálculo da sua magnitude fornece-nos uma imagem, ainda que incompleta, da actividade associada aos principais acidentes tectónicos activos: As fronteiras de placas e as zonas de fractura. O mapa da figura 2 apresenta a probabilidade do risco sísmico da região em termos de pico Ground Acceleration (PGA) para a média e o percentil 85. Numa primeira análise do mapa, verifica-se que as regiões muito activas a sismicidade se apresenta bem definida, verificando-se uma maior concentração de sismos na zona localizada ao longo do Rift Africano.

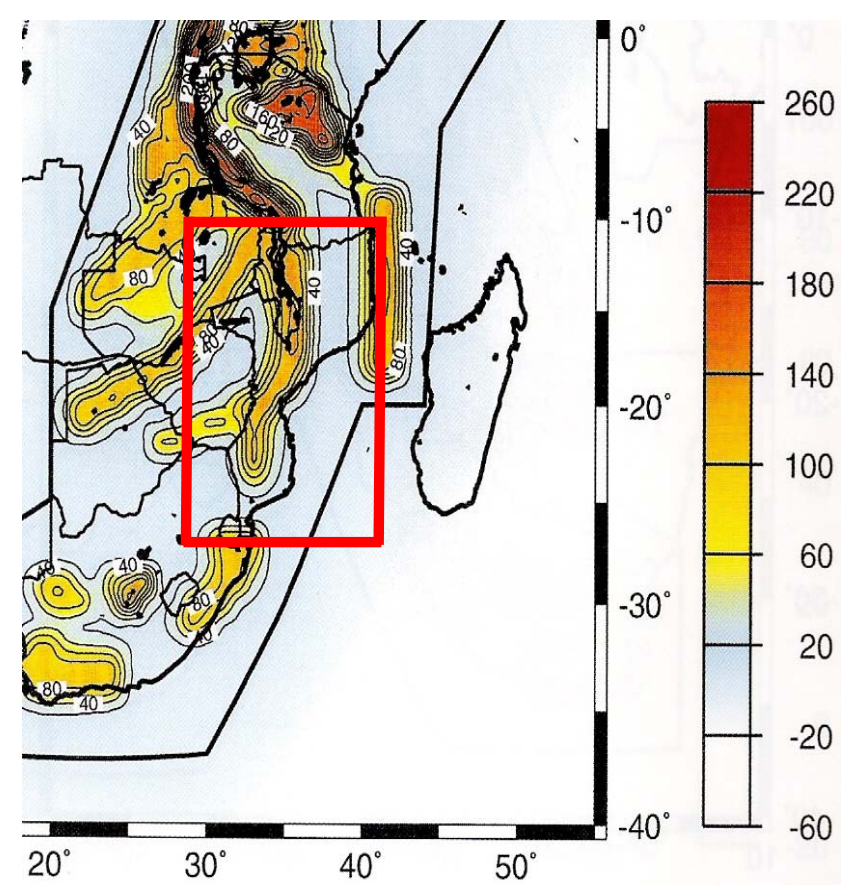


Figura 1. Representa os nílveis de aceleração em termos de probabilidade de PGA (em galões), com $10 \%$ de probabilidade de excedência em 50 anos (período de retorno de 475 anos). O intervalos de contorno é de 20 galões. Máximo PGA é de aproximadamente a 120 galões $(0.12 \mathrm{~g})$, a região em estudo é a demarcada por rectagulo azul no mapa.

A Carta de epicentros, registados no período 1957-2009, destaca duas partes altamente sismológicas no território, a saber:

$1^{\text {a }}$ Parte - Sul do Rift Africano com origem no Lago Niassa, dirigindo-se para o Sul, mais ou menos paralelamente aos meridianos $33^{\circ}-35^{\circ} \mathrm{E}$, até ao paralelo $10^{\circ}-25^{\circ} \mathrm{S}$.

$2^{\mathrm{a}}$ Parte - Canal de Moçambique, onde existem duas partes com alta sismicidade $10^{\circ}-18^{\circ} \mathrm{S} ; 40^{\circ}-42^{\circ} \mathrm{E}$ e $21^{\circ}$ $24^{\circ} \mathrm{S} ; 37^{\circ}-40^{\circ} \mathrm{E}$. Todos os sismos grandes ocorridos e conhecidos em Moçambique, ocorreram nestas duas partes indicadas. A maior frequência de ocorrência de sismos grandes nestas duas regiões, foi no período entre 1950-1957. Neste período, houve dez sismos com magnetude $M \geq 6$ na zona do Rift e quatro sismos na zona do canal de Moçambique com a mesma magnetudee no periodo 1980-2006 foram registados sismos com magnitudes superiores a 7.0 graus.

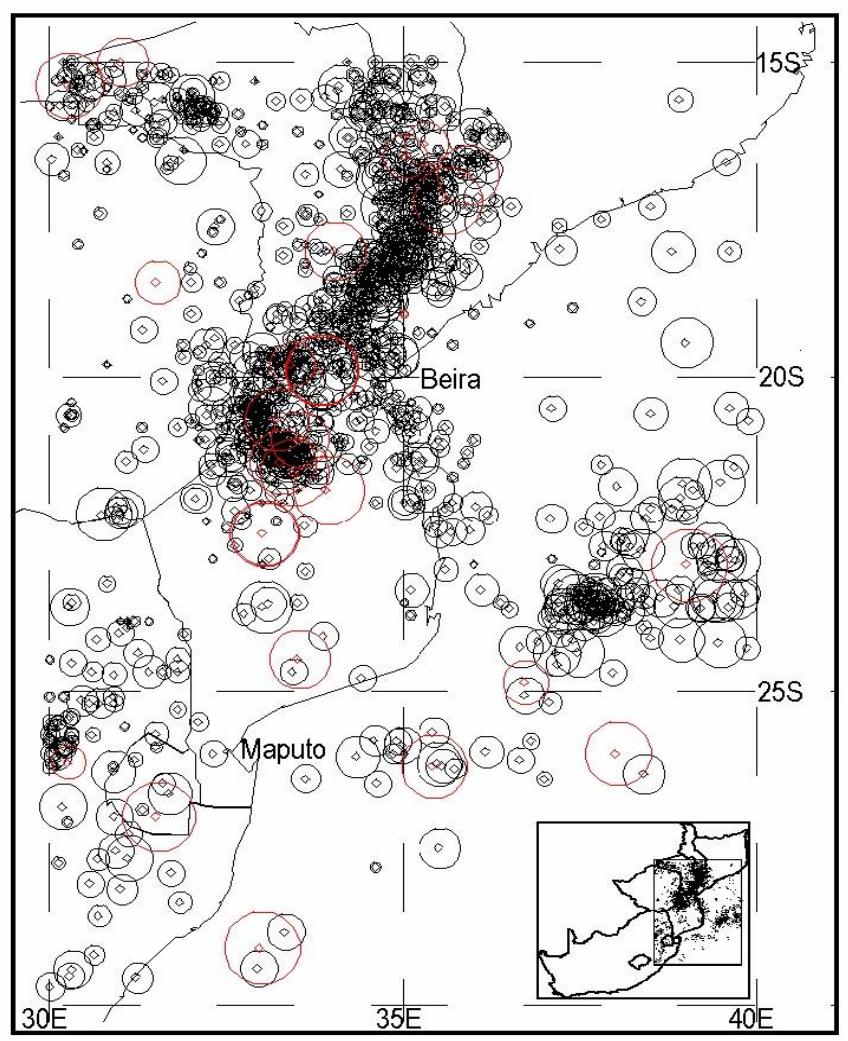

Preto - Representa os dados retirados do "Catálogue of the Incorporated Research Institutes for Seismology (IRIS)" de período de Janeiro de 1964 a Julho de 2006; Vermelho - Representa os dados retirados do "Catalogue of the International Seismological Centre (ISC)" de 1915 (os mais antigo eventos registrados no País) em Dezembro de 1963.

\section{Intensidades sismicas máximas no território nacional.}

Esta, resulta da actividade sísmica anteriormente descrita, há uma necessidade de se tomarem medidas adequadas no sentido de evitar, ou minimizar, os impactos sísmicos quer no que respeita à segurança física dos cidadãos, quer em termos de prejuízos materiais. Estas medidas passam, em primeiro lugar, por uma completa avaliação das intensidades sísmicas máximas a que os diferentes pontos do território estão sujeitos. Os sismos de maior magnitude condicionam essa distribuição e a eles associam-se períodos de recorrência elevados, o que implica que à informação instrumental deve ser acrescida a informação histórica de períodos mais rantigos possível.

Em 1957, foi criado o primeiro Obreservatorio Sismológico, Instalado em Maputo, com o qual até finais dos anos 60 foram registados 44 sísmos de magnitude que variam entre 5.0 a 6.5 , para além de elevado número de sísmos de fraca intensidade. Dos 304 sismos registados ou sentidos neste período, 174 são referentes ao período de 1905-1965 e os restantes aos finais da década 60, O período entre 1957 a 1985 é considerado "período calmo " uma vez que não foram registados muitos abalos sísmicos com magnitude superior a 6.0 graus.

Em 1985 ocorreram dois abalos com magnitude de 6.0 e 6.4 graus ao longo da parte setentrional do Canal de Moçambique, àrea representada pela cor azul no mapa e os restantes ocorreram ao longo do vale do rift representado na figura 4 pela cor amarela.

\section{Sismicidade das regiões atravessada pelo Rift Africano no País}

A distribuição da sismicidade instrumental nas zonas atravessadas pelo rift africano é muito heterogénea e encontra-se essencialmente concentrada nas Províncias de Manica, Nampula e Niassa e no Canal de Moçambique. Esta região apresenta uma actividade sísmica caracterizada por eventos de magnitude moderada que varia de $(M \geq 2,5-5)$ e, ocasionalmente, alguns eventos mais fortes ou inferiores.
Fig. 2. Mapa de epicentros, onde os diâmetros dos círculos indicam os epicentros e que são linearmente proporcionais à magnitude do terremoto, que variam entre 2,5 e 6,8. O símbolo a cor indicam fonte, catálogo e data: 
S Mozambique earthquakes (2006 - 2008)

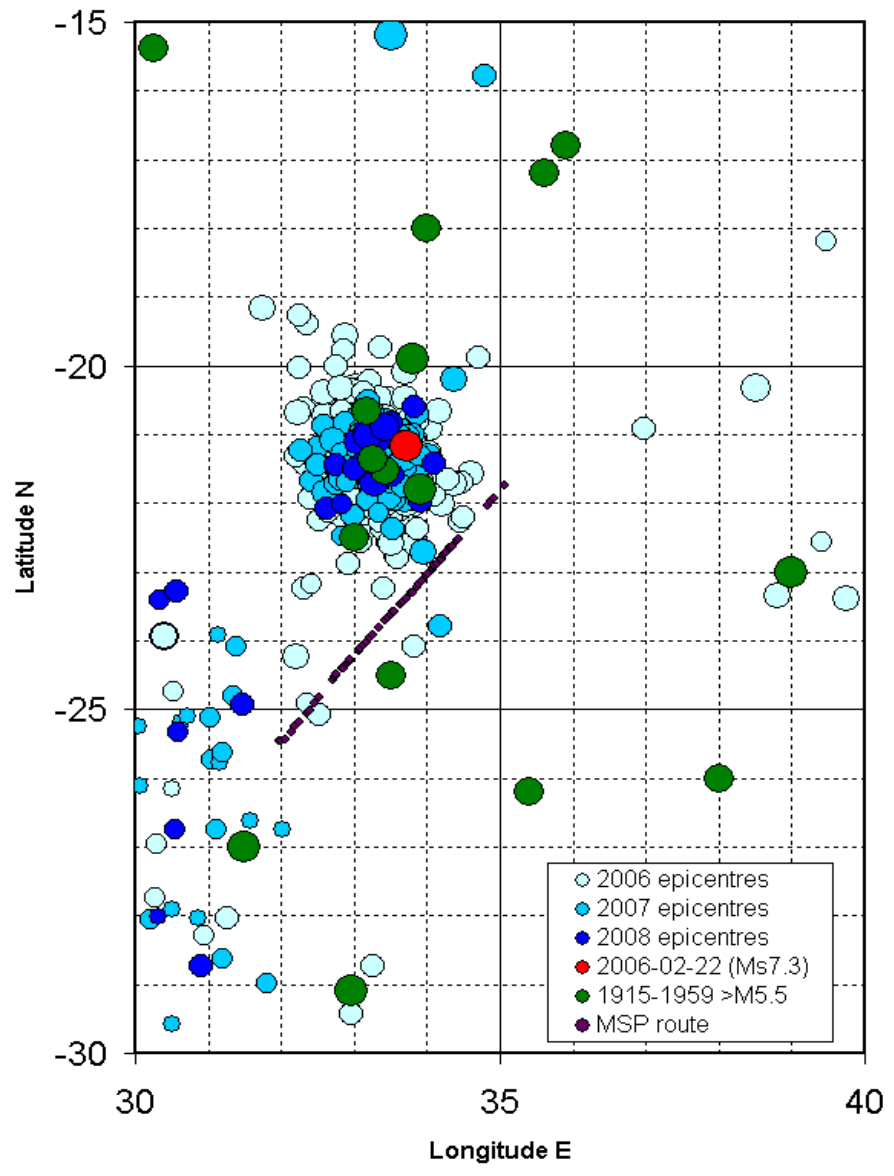

Fig: 3. Epicentro de sismos ocorridos no período 19572008, com destaque a vermelho para o sísmo de 23 de Fevereiro de 2006, são apresentados ainda os epicentros para o período 1915-2008, informação referente a sismicidade histórica do País, todos dados foram obtidos a partir de catálogos e boletins sísmicos da Direcção Nacional de Geologia (DNG).

Pela sua localização dos epicentros, constata-se que os epicentros se encontram dispersos por todo o território, embora se verifiquem maiores concentrações em determinadas regiões, verifica-se ainda que existem zonas com uma sismicidade muito baixa e outras muito elevada, podendo-se verificar este fenómeno no Planalto de Niassa, Matchaze, Massingir, Cabo-delgado, Nampula e parte Este da Zambézia, isto na região norte, sul e centro do País. exceptuando algumas zona da Costa de Moçambique e a parte limítrofe do Lago Niassa, nestas zonas não foram registados sismos grandes com magnitudes $(M \geq 7.0)$, e muito poucos sismos fracos. Situação igual temos na Província de Tete e parte sul de Moçambique.

A partir destes mesmos catálogos e boletins sísmicos, tem-se a informação de que, o período entre 1957-1985, foi um período calmo no que se refere a sismos grandes, isto é, com magnetudes $\geq 6$. No ano de 1985 ocorreram dois sismos junto à costa Norte de Moçambique com magnitudes 6.0 e 6.4 graus respectivamente. Estes dois sismos são considerados como único em virtude do epicentro ter sido no mesmo local e a diferença entre eles ter sido de cinco horas. Na parte continental do Pais, ocorreram dois sismos grandes em Março de 1989, com magnitude de 5.8 e 6.2 graus.

\section{Intensidades máximas no território nacional}

Resulta da actividade sísmica anteriormente descrita, ha uma necessidade de se tomarem medidas adequadas no sentido de evitar, ou minimizar, os impactos sísmicos quer no que respeita à segurança física dos cidadãos, quer em termos de prejuízos materiais. Estas medidas passam, em primeiro lugar, por uma completa avaliação das intensidades sísmicas máximas a que os diferentes pontos do território estão sujeitos. Os sismos de maior magnitude condicionam essa distribuição e a eles associam-se períodos de recorrência elevados, o que implica que à informação instrumental deve ser acrescida a informação histórica de períodos mais rantigos possível. Neste caso, em 1957, foi criado o primeiro Obreservatorio Sismológico, Instalado em Maputo, com o qual até finais dos anos 60 foram registados 44 sísmos de magnitude que variam entre 5.0 a 6.5 , para além de elevado número de sísmos de fraca intensidade. Dos 304 sismos registados ou sentidos neste período, 174 são referentes ao período de 1905-1965 e os restantes aos finais da década 60, O período entre 1957 a 1985 é considerado "período calmo " uma vez que não foram registados muitos abalos sísmicos com magnitude superior a 6.0 graus. Em 1985 ocorreram dois abalos com magnitude de 6.0 e 6.4 graus ao longo da parte setentrional do Canal de Moçambique, e em Março de 1989 ocorreram 2 sismos na parte continental de Moçambique.

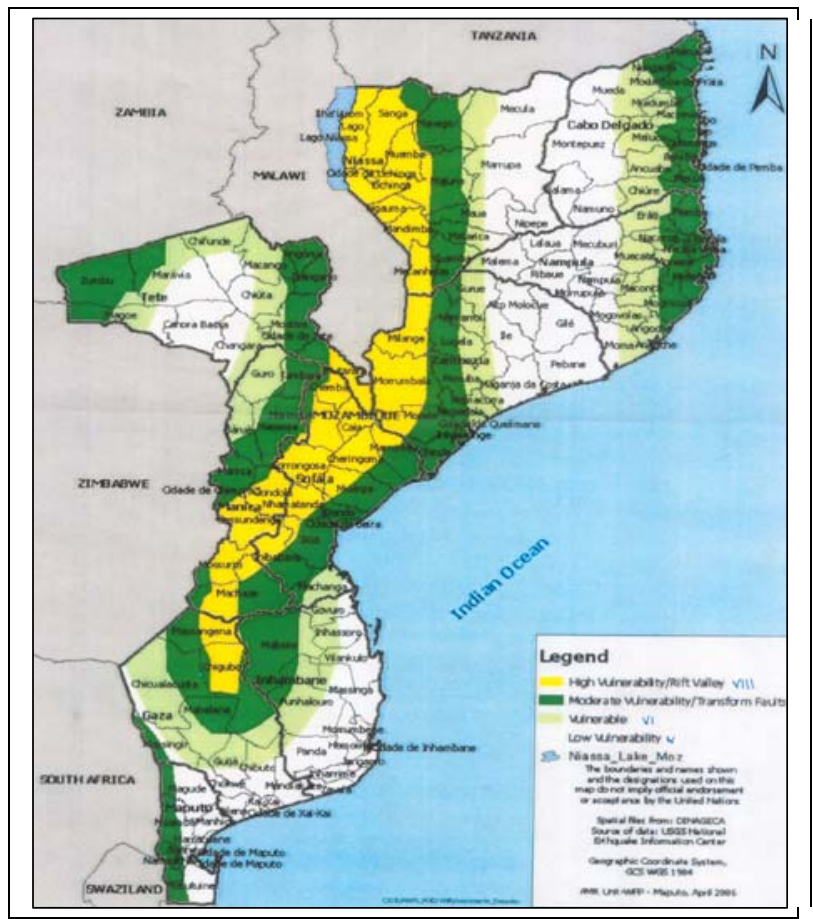

Figura 4. áreas vulneráveis a ocorrência de Sísmos em, 
representa as regiões sismotectónica do País, verifica-se que o Rift Africano (representado pela cor amarela na figura 4 acima), está bem desenvolvido no norte e centro do País, assim, importa referenciar dois aspectos:

1. O Rift iniciou o seu desenvolvimento ou por outra, entrou em actividade na região centro de Moçambique há cerca de 10 milhões de anos;

2. As areias e solos que constituem as camadas de cobertura no sul de Moçambique são de idade inferior a 2 Ma. Então, o início da actividade do Rift na região sul é mais velho que as camadas de cobertura do sul de Moçambique. Isto quer dizer que os elementos tectónicos do Rift (como escarpas abruptas) podem estar soterrados por tais camadas de cobertura. Além da sismicidade referida, a distribuição de epicentros mostra uma dispersão considerável, não sendo fácil correlacioná-los com as falhas activas conhecidas, e este carácter difuso da sismicidade poderá dever-se à sua localização num ambiente tectónico intraplacar.

\section{Dados recentes de sismicidade de Moçambique entre (2006 a 2010)}

Os sísmos mais recentes tem ocorrido nas duas zonas sísmicas citadas acima, prolongamento do Rift e na Região Norte do Canal de Moçambique, por exemplo, de Fevereiro a Março de 2006 ocorreram mais de 50 sismos com magnitudes que variam de 3.3 a 7.0 graus.

Na presente década, o maior sismo ocorreu no dia 23 de Fevereiro de 2006, em Chitobe, Matchaze, com magnitude de 7.5 graus, fez-se sentir em todas Províncias de Moçambique e em alguns Países circunvizinhos, provocou morte de 5 pessoas, 28 feridos e destruição de mais de 280 casas além de outras tantas que sofreram fissuras na sua estrutura.

No o ano de 2010, já foram registados sismos com magnitude superior a 4,3 da escala de Richter em algumas zonas das regiões Centro (Matchaze), Zona Costeira do Norte do País (Angoche) e Sul (Bilene e Massingir), tendo causado alguns danos materiais e humanos no Distrito de Angoche na Província de Nampula.

\section{Conclusões}

O território moçambicano é responsável por uma significativa actividade sísmica na região, devido a sua localização tectónica. De uma forma geral, a sismicidade aumenta de intensidade de norte para centro do País, esta sismicidade pode ser originada em acidentes geológicos localizados em terra, como no vale do rift onde tem ocorrido muitos dos sismos registados desde 1957 a 2008, ou em estruturas localizadas no oceano índico. Pressupõe-se ainda que a ocorrência de sismos de grande magnitude nas zonas submersas pode dar origem a tsunamis.

Com os dispositivos de monitoração sísmica existentes actualmente, é possível detectar e localizar os eventos com magnitude mínima, e obter muito mais informação sobre a sismicidade do territorio. No entanto, dada a distribuição da sismicidade e a localização das estações, verifica-se que subsistem ainda muitos problemas que têm a ver com a deficiente cobertura da rede sismográfica para os sismos ocorridos nas zonas de Canal de Moçambique, particularmente para os com localização epicentral no oceano índico, resultando em soluções epicentrais mal determinadas, situação que só poderá ser combatida com a instalação de observatórios para monitorar Tsunames e ampliação da rede sismográfica nacional, em especial a rede de estações de banda larga (broadband).

\section{AGRADECIMENTOS}

Agradeço a Direcção Nacional de Geologia, e todos os colegas de trabalho que desponibilizaram algumas informações que vem contidas neste artigo;

Agradeço o Instituto de Astronomia, Geofisica e Ciências Atomosféricas da USP.

\section{REFERÊNCIAS}

Hartnady C.J.H. Earthquake hazard in Africa: perspectives on the Nubia-Somalia boundary. S. Afr. J. Sci., 98, 425-428.

Hartnady C.J.H., 2003. Recent active faults on the gas pipeline route between Temane and Ressano Garcia, Mozambique. Unpublished Umvoto Africa report to Geopractica and Sasol Gas Ltd., 31 pp, 12 Figs \& 3 Appends.

Hartnady C.J.H, 2006. Seismotectonics of Southern Mozambique. 21st Colloquium on African Geology (CAG21), Maputo (3-5 July 2006), Mozambique, Abstracts Volume p. 408-410.

C.J.H. Hartnady, Umvoto Africa (Pty) Ltd, South Africa in association with Geopractica, Mozambique to South Africa Gas Pipeline (MSP), Seismic Investigation: Preliminary Desktop and Field Reconnaissance Study, June 2008;

Seismic hazard assessment in Eastern and Southern Africa, volume 4, Dez. 1999. 